\title{
Histo-Morphometric Demonstration of Cardiotoxic Effects of Aspartame on Mice
}

\author{
D.R Gudadhe ${ }^{1}$, S.S Talhar ${ }^{2}$, P. Bokariya ${ }^{3}$, M.R Shende ${ }^{4}$, A.M Tarnekar ${ }^{5}$. \\ ${ }^{1}$ Junior resident III, ${ }^{2}$ Senior Resident, ${ }^{3}$ Assistant Professor, ${ }^{4}$ Professor \& Head \\ ${ }_{, 5}^{5}$ Professor*. \\ ${ }^{1,2,3,4,5,}$ Dept of Anatomy, Mahatma Gandhi Institute of Medical Sciences, Sevagram, Wardha (Maharashtra, \\ India) \\ Pin- 442102
}

\begin{abstract}
:
Aim \& Objectives: To demonstrate microscopic structural alterations, if any, in myocardium of adult Swiss albino mice as an irreversible effect of neonatal exposure of Aspartame.
\end{abstract}

Material \& Methods: Study was conducted on Swiss albino mice grouped into 25 control and 25 experimental. Aspartame was injected intraperitoneally in experimental group of neonatal mice at a dose of $100 \mu \mathrm{g} / \mathrm{g}$ body weight per day for two weeks while age matched control group of mice received same volume of normal saline intraperitoneally. Mice of both the groups were sacrificed by euthanasia at 60 days of age or above. Observations of weight of heart as well as histo- morphometry of diameter of cardiac myocyte were recorded.

Results: There was significant increase in the weight of heart and diameter of cardiac myocytes in experimental group. However the number of cardiac myocytes was apparently reduced in experimental group with a corresponding increase in ground material of myocardial stroma.

Conclusion: Our observations suggest residual micro structural changes in myocardium of adult mice in the form of compensatory hypertrophy of myocytes as a remote toxic effect of Aspartame probably resulting from myocardial damage during dosing period of Aspartame in neonatal mice. Thus the changes are irreversible and compensatory but not fatal, that may be compromising with life.

Keywords: Aspartame, Myocardium, Heart weight, Cardiac myocyte, Histomorphometry.

* indicates co-author

\section{INTRODUCTION:}

The first insecurity shook the artificial sweetener market in 1970, when cyclamate was banned by FDA in USA for its alleged causative role of cancer in experimental animals ${ }^{1}$. It nearly took 20 years to take away from market this 'sweet poison'. Still in all other countries except USA, cyclamate is used today, especially in combination with other artificial sweeteners. As necessity is the need of invention, with increasing demand for low calorie artificial sweetener, Aspartame entered with promising potential. Aspartame is an artificial, nonsaccharide sweetener, popular amongst diabetics and calorie conscious individuals. It was discovered in 1965 and permitted in 1981 by FDA for human use. Since then worldwide research has been carried out on its safety in human. In spite of being projected as potentially toxic compound by several studies, the use of Aspartame still continues. In absence of consistent findings of toxic role of Aspartame in animal tissues especially on heart, the present study was carried out in mice.

Aim of study: The study was carried out with the main aim to document toxic role of aspartame in heart of mice by comparing the microscopic structure of myocardium of two groups of mice. The objectives were to record macroscopic and microscopic findings in heart by observing qualitative (histological) and quantitative (histomorphometric) differences (if any) in two groups of heart and then to interpret the data by applying suitable statistical method.

Material \& Methods: The present study- a case-control based histological study, was carried out in the Research lab of Anatomy department of our institute. Due permission was obtained from Institutional animal Ethical Committee. The 60 mice in the study were divided in two equal age matched groups of 30 each. The neonatal mice were procured from registered professional breeders. Commercial food and hygienic drinking water was provided ad libitum and standard housing arrangement was provided to animals in Institutional animal house throughout experimental period ${ }^{2}$. Aspartame, reconstituted in normal saline, was injected 
intraperitoneally in experimental group of neonatal Swiss albino mice at a dose of $100 \mu \mathrm{g}$ Aspartame per gram body weight per day for two weeks. Control group of neonatal mice received same volume of saline

intraperitoneally. Adult mice of both groups were sacrificed by euthanasia at the age of 60 days or above and histological sections of myocardium were prepared after routine $\mathrm{H} / \mathrm{E}$ staining for microscopy ${ }^{3}$, histomorphometry and microphotography.

Histomorphometry: Diameter of the longitudinally cut cardiac myocyte bearing a nucleus, was recorded using a calibrated ocular micrometer scale. Stage micrometer was used for calibration.

Statistical analysis: Numerical values of observation of the two groups were subjected to the statistical analysis for significance by Student's unpaired ' $t$ ' test.

\section{OBSERVATIONS AND RESULT:}

On observing the weights of freshly dissected hearts of adult mice we found an increase in experimental group (Table No. 1) which was found to be statistically significant. There was also a significant increase in weight of mice in experimental group of animals. On critically comparing the histological structure of myocardium in stained sections of hearts of two groups, we found increase in diameter of cardiac myocytes, increase in ground material of myocardial stroma, an apparently reduced number of cardiac myocytes and no sign of active inflammatory response in myocardium in experimental group. The histomorphometric observation of diameter of the longitudinally cut cardiac myocyte indicated increase in the diameter of cardiac myocyte in experimental group and the difference in mean value of two groups was statistically significant (Table No. 2).

\section{DISCUSSION:}

There have been reports of alleged toxic potential of commercial sweeteners in past and there was growing awareness towards such reports in the general population. Inspite of being projected as a safe, low caloric dietary sweetener, which has made it a very popular table top sweetener, there have been controversies about its safety potential right from the beginning. Various studies document the toxic effects of Aspartame or its metabolic products on different organ systems of animal tissue. However, the reports of presumptive cardiotoxic effects of Aspartame, especially in human or mammals are scanty and mostly based on documentation of some clinical parameters like alteration of pulse rate, blood pressure and electrocardiographic changes $^{4}$ or biochemical parameters 5 . Our attempt was to document the possible alteration in histological structure of myocardium by Aspartame, using mice as a small mammalian model. The effect of Aspartame was studied in hearts of adult mice after administration of Aspartame in neonatal life, with the justification that acute toxicity of Aspartame is common and is mostly reported by alteration of clinical parameters but usually such effects are reversible. We have presumed that such acute toxicity might have been there in our experimental set of mice, but it was not lethal or disabling since none of our experimental mouse died or showed any adverse alteration of vital parameters during and after dosing period. Thus whatever irreversible changes resulted from such toxicity would be observed any time in life and that would reflect residual structural alteration in myocardium. Our observations of the increased diameter of myocytes (Fig No. 3, 4) and widened unstained intervals between the myofibers (Fig No. 5, 6) suggest a hypertrophy of myocytes and gain in the semisolid matter (ground substance) including fluid component in myocardial stroma. Several other experimentations with rodent myocardial tissue with other toxic substances like alcohol ${ }^{6}$ and chloroquine ${ }^{7}$ has documented hypertrophic cardiac myocytes. The gain in weight of the heart in our study group of mice appears to be mainly due to increase of semisolid matrix in the stroma of myocardium. The contribution by hypertrophic effect of cardiac myocyte does not seem to be the cause of weight gain. Since our histological observation did not have any sign of a persistent inflammatory reaction, the reason behind hypertrophy of cardiac myocyte could possibly be to compensate the loss of myocytes at an early dosing period. As an adaptive response of muscular tissue to compensate the overload, the myocytes undergo hypertrophy as the skeletal and cardiac muscles are generally not capable of cell divisions ${ }^{8}$.

\section{Conclusion:}

In the present study we have observed hypertrophy of cardiac myocytes. Diameter of cardiac myocytes was more in experimental group and the difference with control group was statistically significant. Also there was statistically significant increase in weight of heart in experimental group. Our observation thus document remote and residual (irreversible) but not lethal effect of neonatal exposure of Aspartame in adult mice.

\section{Acknowledgement:}

Authors gratefully acknowledge the technical assistance of Mr V P Kavinesan, Mrs Chhaya Chauhan and Mr Ashok Wahiwatkar. 


\section{Bilbliography:}

[1] FDA report. FDA extends ban on cyclamates. Science 1970; 169: 962.

[2] Chatterjee TK. The laboratory mouse. In: Handbook of Laboratory mice and rats $1993 ; 1^{\text {st }}$ edition (Publ. Chatterjee K. K, Calcutta): pp 3- 12 .

[3] Drury RAB and Wallington EA. Preparation and fixation of tissues. In: Carleton's Histological Technique. $4^{\text {th }}$ edition. New York: Oxford University Press; 1967. pp 36- 56.

[4] Burkhart CG. 'Lone' atrial fibrillation precipitated by monosodium glutamate and aspartame. International Journal of Cardiology 2009; 137 (3): 307- 8.

[5] Roberts HJ. Aspartame-induced dyspnea and pulmonary hypertension. Townsend Letter for Doctors and Patients 2004 (2); 237: 6465.

[6] Rawlani SS, Ghosh SK, Ingole IV, Pal AK, Tarnekar AM, Waghmare JE, Rawlani SM. Effect of alcohol on myocardium of miceA histological study. Journal of Anatomical Society of India 2009; 58 (1): 19- 23.

[7] Izunya AM, Nwaopara AO, Anyanwu LC, Odike M, Oaikhena GA, Bankole JK, Okhiai O. Effect of chronic oral administration of chloroquine on the histology of the heart in Wistar rats. Biology and Medicine 2011; 3 (4): 1 - 6 .

[8] Kumar V, Abbas AK, Fausto N. Cellular Adaptations, Cell Injury \& Cell Death. In: Robbins \& Cotran Pathologic Basis of Disease. $7^{\text {th }}$ edition. Philadelphia: Elsevier; 2004. pp 3- 44.

\section{List of Tables}

Table No. 1: Comparison of average weight of heart in two groups

\begin{tabular}{|c|c|c|c|c|}
\hline Experimental Group & Control Group & Difference in weight & t-value & $\mathrm{p}$-value \\
\hline $0.24 \pm 0.06$ & $0.19 \pm 0.01$ & $0.05 \pm 0.01$ & 3.82 & $\begin{array}{c}0.000 \\
\mathrm{~S}, \mathrm{p}<0.05\end{array}$ \\
\hline
\end{tabular}

Table No. 2: Comparison of mean diameter of cardiac myocyte in two groups

\begin{tabular}{|c|c|c|c|c|c|}
\hline & Mean $($ in $\mu \mathrm{m})$ & SD & Differencet-value & $\mathrm{p}$-value \\
\hline Experimental & 10.58 & 1.06 & $1.24 \pm 0.23$ & 5.30 & $\begin{array}{c}0.000 \\
\mathrm{~S}, \mathrm{p}<0.05\end{array}$ \\
\hline Control & 9.33 & 0.50 &
\end{tabular}

List of Figures

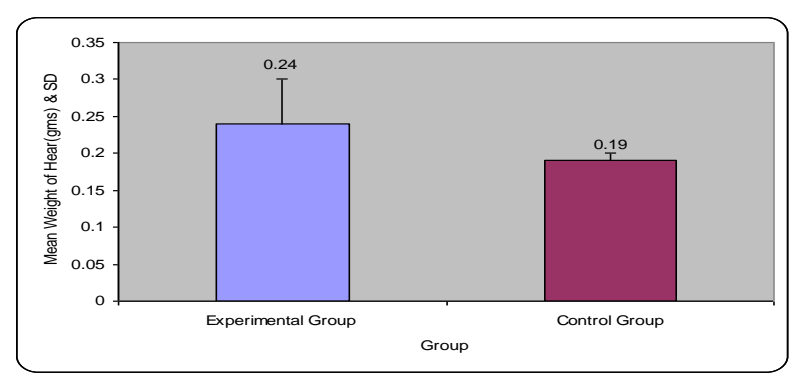

Fig No. 1: Graphical representation of difference in average weight of hearts in two groups.

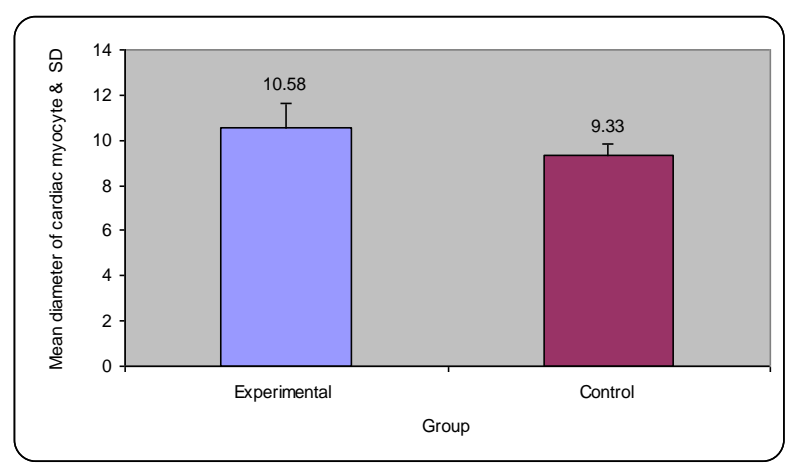

Fig No. 2: Graphical comparison of mean diameter of cardiac myocyte in two groups. 


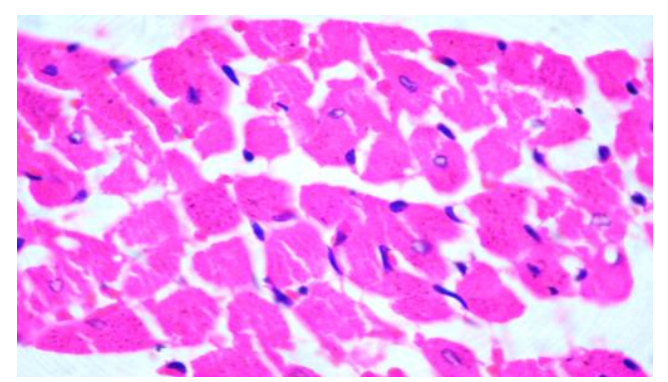

Fig No. 3: Showing H\& E stained cross sectional view of control group (X1000)

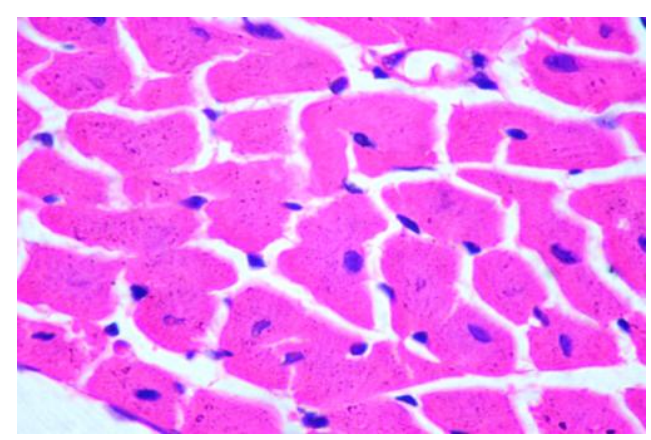

Fig No. 4: Showing increased diameter of cardiac myocyte in $\mathrm{H} \& \mathrm{E}$ stained cross section in experimental group (X1000)

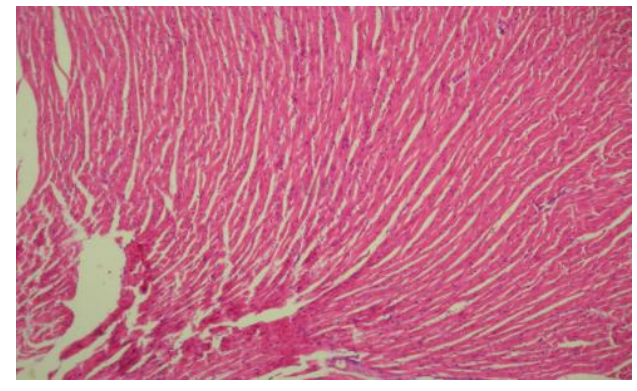

Fig No. 5: Showing H\& E stained longitudinal section of control group (X100)

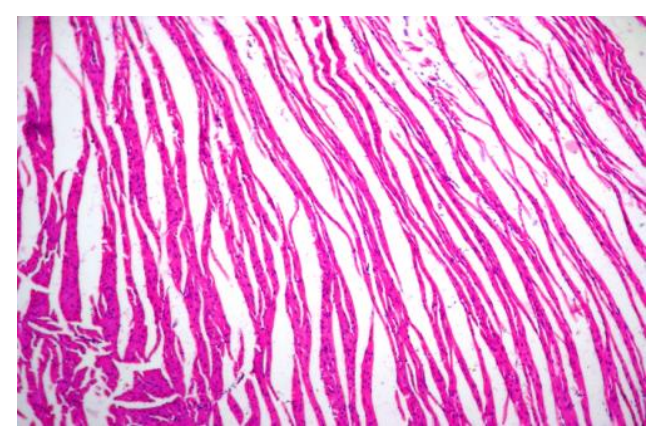

Fig No. 6: Showing increased stroma between cardiac myocyte in $\mathrm{H} \& \mathrm{E}$ stained longitudinal section in experimental group (X100) 